NASA/TM-2003-212116

Development and Utility of a Piloted Flight Simulator for Icing Effects Training

Thomas P. Ratvasky

Glenn Research Center, Cleveland, Ohio

Richard J. Ranaudo

Aerolin LLC, Loudon, Tennessee

Billy P. Barnhart, Edward G. Dickes, and David R. Gingras

Bihrle Applied Research, Inc., Jericho, New York 
Since its founding, NASA has been dedicated to the advancement of aeronautics and space science. The NASA Scientific and Technical Information (STI) Program Office plays a key part in helping NASA maintain this important role.

The NASA STI Program Office is operated by Langley Research Center, the Lead Center for NASA's scientific and technical information. The NASA STI Program Office provides access to the NASA STI Database, the largest collection of aeronautical and space science STI in the world. The Program Office is also NASA's institutional mechanism for disseminating the results of its research and development activities. These results are published by NASA in the NASA STI Report Series, which includes the following report types:

- $\quad$ TECHNICAL PUBLICATION. Reports of completed research or a major significant phase of research that present the results of NASA programs and include extensive data or theoretical analysis. Includes compilations of significant scientific and technical data and information deemed to be of continuing reference value. NASA's counterpart of peerreviewed formal professional papers but has less stringent limitations on manuscript length and extent of graphic presentations.

- TECHNICAL MEMORANDUM. Scientific and technical findings that are preliminary or of specialized interest, e.g., quick release reports, working papers, and bibliographies that contain minimal annotation. Does not contain extensive analysis.

- CONTRACTOR REPORT. Scientific and technical findings by NASA-sponsored contractors and grantees.
- CONFERENCE PUBLICATION. Collected papers from scientific and technical conferences, symposia, seminars, or other meetings sponsored or cosponsored by NASA.

- SPECIAL PUBLICATION. Scientific, technical, or historical information from NASA programs, projects, and missions, often concerned with subjects having substantial public interest.

- TECHNICAL TRANSLATION. Englishlanguage translations of foreign scientific and technical material pertinent to NASA's mission.

Specialized services that complement the STI Program Office's diverse offerings include creating custom thesauri, building customized databases, organizing and publishing research results ... even providing videos.

For more information about the NASA STI Program Office, see the following:

- Access the NASA STI Program Home Page at http://www.sti.nasa.gov

- E-mail your question via the Internet to help@sti.nasa.gov

- Fax your question to the NASA Access Help Desk at 301-621-0134

- Telephone the NASA Access Help Desk at 301-621-0390

- Write to:

NASA Access Help Desk

NASA Center for AeroSpace Information 7121 Standard Drive

Hanover, MD 21076 
NASA/TM-2003-212116

AIAA-2003-0022

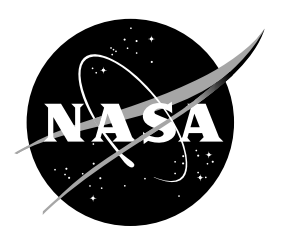

\section{Development and Utility of a Piloted Flight Simulator for Icing Effects Training}

Thomas P. Ratvasky

Glenn Research Center, Cleveland, Ohio

Richard J. Ranaudo

Aerolin LLC, Loudon, Tennessee

Billy P. Barnhart, Edward G. Dickes, and David R. Gingras

Bihrle Applied Research, Inc., Jericho, New York

Prepared for the

41st Aerospace Sciences Meeting and Exhibit

sponsored by the American Institute of Aeronautics and Astronautics

Reno, Nevada, January 6-9, 2003

National Aeronautics and

Space Administration

Glenn Research Center 


\section{Acknowledgments}

The authors wish to thank Tom Bond from the NASA GRC Icing Branch, Kurt Blankenship from the NASA GRC

Flight Operations, and Kevin Burke from the NASA GRC Imaging Technology Center for their inputs to the development of this icing training tool. We also would like to thank the sponsors from the System Wide Accident

Prevention Project for their continued support during this development cycle.

Trade names or manufacturers' names are used in this report for identification only. This usage does not constitute an official endorsement, either expressed or implied, by the National Aeronautics and Space Administration.

Available from

NASA Center for Aerospace Information 7121 Standard Drive

Hanover, MD 21076
National Technical Information Service 5285 Port Royal Road Springfield, VA 22100 


\title{
DEVELOPMENT AND UTILITY OF A PILOTED FLIGHT SIMULATOR FOR ICING EFFECTS TRAINING
}

\author{
Thomas P. Ratvasky \\ National Aeronautics and Space Administration \\ Glenn Research Center \\ Cleveland, Ohio 44135 \\ Richard J. Ranaudo \\ Aerolin LLC \\ Loudon, Tennessee 37774
}

Billy P. Barnhart, Edward G. Dickes, and David R. Gingras

Bihrle Applied Research, Inc.

Jericho, New York 11753

\begin{abstract}
A piloted flight simulator called the Ice Contamination Effects Flight Training Device (ICEFTD), which uses low cost desktop components and a generic cockpit replication is being developed. The purpose of this device is to demonstrate the effectiveness of its use for training pilots to recognize and recover from aircraft handling anomalies that result from airframe ice formations. High-fidelity flight simulation models for various baseline (non-iced) and iced configurations were developed from wind tunnel tests of a subscale DeHavilland DHC-6 Twin Otter aircraft model. These simulation models were validated with flight test data from the NASA Twin Otter Icing Research Aircraft, which included the effects of ice on wing and tail stall characteristics. These simulation models are being implemented into an ICEFTD that will provide representative aircraft characteristics due to airframe icing. Scenariobased exercises are being constructed to give an operational-flavor to the simulation. Training pilots will learn to recognize iced aircraft characteristics from the baseline, and will practice and apply appropriate recovery procedures to a handling event.
\end{abstract}

\subsection{Introduction}

In response to a White House Initiative to reduce aviation accidents, NASA formed the Aviation Safety Program (AvSP) in 1999. This seven-year program has been tasked to reduce aviation accident rates by $80 \%$ by 2007 and by $90 \%$ by 2017 . Accident and incident reports were analyzed to focus efforts on areas of highest return. These studies showed that $13 \%$ of all weather-related accidents were due to airframe icing.

A complementary study of twenty-four accidents was performed by the Commercial Aviation Safety Team (CAST) Loss of Control Joint Safety Analysis Team to develop intervention strategies that will reduce loss of control accidents. Icing was a contributing factor in three of the twenty-four accidents reviewed. Several highly-ranked interventions and research recommendations addressed the need for upset recovery training with high-fidelity simulation and the requirement for improved aerodynamic modeling at the stall and post-stall region of the envelope ${ }^{1}$.

NASA Glenn's Icing Branch has been addressing these issues by developing a number of tools to supplement pilot training that consists of educational \& training videos ${ }^{2,3,4}$ and computer-based training materials ${ }^{5}$. Additionally, an Aircraft lcing Effects Training task, which is a component of NASA's System Wide Accident Prevention Project of AvSP, is currently underway to develop a piloted flight training device that simulates aerodynamic icing effects for realistic pilot training scenarios.

The Ice Contamination Effects Flight Training Device (ICEFTD) will demonstrate a means of training pilots for the adverse effects of icing on airplane performance and handling. Currently, most flight simulators address icing effects by increasing weight. Although this approach will cause stall speeds to increase, it does not account for the change in aerodynamics resulting from ice contamination. As a result, it does not address icing effects on stability and controllability, and therefore does 
not provide representative handling qualities due to the icing condition being simulated.

In order to advance the flight simulator technology, the NASA Glenn Research Center teamed with Bihrle Applied Research and the Wichita State University in 1998 to develop an icing effects flight training device concept demonstrator. The intent of this demonstrator is to exhibit a methodology for deriving and validating icing effects simulation models, and provide a platform to evaluate the utility of a flight training device for icing effects training. Should the evaluation of such a device prove positive, then the technology used to develop this demonstrator could be a valuable addition to other flight training simulators. By getting icing effects into flight training simulators used for initial and recurrent training, pilots could experience representative icing induced aircraft handling characteristics, especially in failure case training scenarios. This capability will enhance safety by allowing pilots to recognize important visual and tactile cues associated with an icing event, which they now only experience for the first time in a real flight situation. As in stall and windshear training, pilots will be better equipped to employ the correct procedures and techniques to affect a recovery to a safe flight condition.

This report reviews simulation models which were developed and validated from wind tunnel and flight test data. It then describes icing effects in the flight training device along with potential training exercises for pilot evaluations, and concludes with a summary of pilot training goals, current accomplishments, and suggestions for ICEFTD technology implementation.

\subsection{Development and Validation of Simulation Models}

A number of steps were taken to develop accurate and robust icing effects flight simulation models. The general approach was to use a combination of experimental data from wind tunnels (using sub-scale, complete airplane models with ice shapes), and limited flight data to derive aerodynamic flight characteristics.

\subsection{Aircraft Selection}

The first step was to select an aircraft to simulate. The aircraft selected for this demonstration was a DeHavilland DHC-6 Twin Otter, which has been employed by NASA-
Glenn as an icing research aircraft for the past twenty years. Using this aircraft, NASA has accumulated an extensive aerodynamic data base that is coupled to measured in-flight icing conditions and to testing with artificial ice shapes $^{6,7}$. The Twin Otter was also used in NASA's Tailplane Icing Program (TIP) ${ }^{8}, 9,10$, providing flight data that forms the basis for understanding tailplane stall phenomena and recovery procedures as described in Reference 2.

\subsection{Ice Shape Selection}

The second step was to determine ice shape configurations to be used in the project. To maintain an operational setting, ice shapes were developed for a failed ice protection system scenario using the NASA ice accretion code, LEWICE 2.0. The icing conditions selected for this scenario simulate a $22 \quad 1 / 2$ minute hold, and are listed in Table 1 below.

Table 1: Icing Conditions for LEWICE

\begin{tabular}{|l|l|}
\hline Liquid Water Content & $0.5 \mathrm{~g} / \mathrm{m}^{3}$ \\
\hline Droplet Size & $20 \mu \mathrm{m}$ \\
\hline Total Temperature & $-4^{\circ} \mathrm{C}$ \\
\hline Airspeed & $120 \mathrm{knots}$ \\
\hline Angle of Attack & $\begin{array}{l}2^{\circ} \text { for wing, } 0^{\circ} \text { for } \\
\text { tails }\end{array}$ \\
\hline Icing Time & $221 / 2$ minutes \\
\hline Pressure Altitude & $6000 \mathrm{ft}$ \\
\hline
\end{tabular}

These icing conditions and the full-scale 2D coordinates of the Twin Otter wing, horizontal tail and vertical tail were used as inputs for the LEWICE code. The outputs from the code were the 2D coordinates of the predicted ice shape for each airfoil surface (see Figure 1 to Figure 4).

\subsection{Wind Tunnel Tests}

After determining the full scale ice shapes that represented an operational scenario, the effort focused on developing small-scale ice shapes for small-scale (approximately 7\%-scale) wind tunnel models to obtain equivalent full-scale iced aeroperformance characteristics ${ }^{11}$. The general outcome of this effort was a set of simple stall strips that represented the geometric height and position of the ice horn on the suction side of the airfoil. For the horizontal tail, the scaled ice shape was a 1/16" square piece of balsa wood mounted on the airfoil in a position consistent with the lower surface horn (Figure 2). This was a substantial and critical step in order to develop accurate simulation models. 
After the ice shape development methods were understood, a $6.5 \%$-scale complete aircraft model of a Twin Otter was fabricated and tested at the Wichita State University 7'x10' Low Speed Wind Tunnel (Figure 5) and the Bihrle Applied Research Large Amplitude Multi-Purpose Wind Tunnel. These comprehensive wind tunnel tests obtained force and moment data over a wide range of angle of attack $\left(-20^{\circ}\right.$ to $\left.+40^{\circ}\right)$ and sideslips $\left( \pm 30^{\circ}\right)$ for the baseline (no-ice) configuration, a Horizontal Tail Ice configuration, and an All Iced (Wing, Horizontal and Vertical Tail Ice) configuration.

\subsection{Simulation Model Development}

The development of a flight simulator involves modeling external physical contributions that act on the air vehicle to compute a new vehicle state and presenting observations of those states to the pilot via visual, tactile, aural, or vestibular means. The flight model, as discussed herein, is the component of the simulation that implements the physics of flight and provides state observations to the rest of the simulator. Typical subcomponents of the flight simulation model are equations of motion, propulsion model, ground reaction, aerodynamics model, and flight control model. The development and validation of each of these components are described in detail in References 12 and 13. For brevity, only a portion of the aerodynamic model is discussed below.

\section{AERODYNAMIC MODEL}

The main effort of the flight model development was to establish a successful methodology for modeling the aerodynamic effects of icing conditions. The general approach was to use a combination of experimental data from the wind tunnel and flight test data to derive the aerodynamic flight characteristics. The baseline aerodynamics model was developed using both wind-tunnel data and flight-extracted parameters.

The wind tunnel data were analyzed to determine the model structural dependencies and to insure the preservation of all nonlinear effects. The initial definition of the basic airframe was built from the most significant functional dependencies, which for this aircraft were angle of attack, angle of sideslip and flap deflection. Increments were determined for control deflections, dynamic damping, and power effects.
An example of the longitudinal component of the aerodynamics model structure is shown in the build up of the pitching moment. The pitching moment coefficient modeling reflects its functional dependencies on angle of attack, sideslip, flap deflection, elevator deflection, rotation rate and pitch rate. The total coefficient is produced as a sum of several terms that are each tabular data with the shown dependencies.

$$
\begin{aligned}
\mathrm{C}_{\mathrm{m}_{\text {TOTAL CLEAN }}} & =\mathrm{C}_{\mathrm{m}_{\text {BASIC }}}(\alpha, \beta, \delta \mathrm{f}) \\
& +\Delta \mathrm{C}_{\mathrm{m}_{\mathrm{DE}}}(\alpha, \delta \mathrm{e}, \delta \mathrm{f}) \\
& +\Delta \mathrm{C}_{\mathrm{m}_{\mathrm{ROT}}}(\alpha, \Omega \mathrm{b} / 2 \mathrm{~V} * \mathrm{SGN}(\beta),|\beta|, \delta \mathrm{f}) \\
& +\Delta \mathrm{C}_{\mathrm{m}_{Q}}(\alpha, \mathrm{q} \overline{\mathrm{c}} / 2 \mathrm{~V}, \delta \mathrm{f})
\end{aligned}
$$

The first table, $C_{m_{B A S I C}}$, represents the static pitching moment coefficient for the basic clean configuration as a function of angle of attack, sideslip angle and flap deflection. The incremental coefficient due to elevator deflection for the clean configuration, $\Delta \mathrm{C}_{\mathrm{m}_{\mathrm{DE}}}$, is modeled as an additional table with the functional dependencies shown. The aircraft's dynamic damping characteristics are represented in the next two sets of tables. The incremental pitching moment coefficient due to rotation about the velocity vector is modeled by the table $\Delta \mathrm{C}_{\mathrm{m}_{\mathrm{ROT}}}$. The rotational effect due to sideslip for the longitudinal coefficients is symmetrical, such that the increment for a positive sideslip and rotation rate is the same as that for the same magnitude negative sideslip and rotation rate, and has been mechanized accordingly by the functional dependency on the product of the rotation rate multiplied by the sign of the sideslip angle and the absolute value of the sideslip angle. The body-axis pitch rate damping, $\Delta \mathrm{C}_{\mathrm{m}_{\mathrm{Q}}}$, is mechanized as an incremental table that is a function of pitch rate, as well as angle of attack and flap deflection.

A similar buildup and mechanization is made for the equations that govern the remaining forces and moments of the no-ice baseline configuration.

When considering the iced cases, the model structure remained the same, but the data within the tables differed due to the effect ice had on the respective aerodynamics. This model development process for the baseline and iced configurations is represented in Figure 6. 


\subsection{Simulation Model Validation}

Three distinct aerodynamic simulation models resulted from the development effort one for each ice configuration: "No-Ice" (baseline), "Horizontal tail ice only" (ICE01), and "All-Iced" (ICE02). Each of these simulation models required validation with flight test data.

Although NASA had some flight data for the baseline case, no data for the specific ice shape geometry existed to validate the iced cases. NASA conducted a flight test to collect the fullscale flight dynamics required for this validation effort $^{14}$. Over 575 maneuvers were conducted in a 29 flight hour project with the Twin Otter in the No-Ice, Horizontal tail ice, and "All-Iced" configurations (Figure 7). These maneuvers were parsed into discrete files which were then used in the validation effort described below.

\section{Overdrive Equation Error Analysis}

'Overdrive', the validation tool used in this analysis, is a component in the Bihrle Applied Research D-Six ${ }^{\circledR}$ simulation software. 'Overdrive' allows the validation of the simulation aerodynamic database against flight-extracted data using the process illustrated in Figure 8 . At each time slice, extraction of aerodynamic force and moment coefficients from the flight-recorded time history occurs as shown on the right side of Figure 8. Linear accelerations, angular rates and angular positions are measured by the flight test instrumentation package. Angular rates are numerically differentiated to obtain the angular accelerations of the vehicle. After the removal of the inertial effects, the remainder is nondimensionalized to calculate the aerodynamic force and moment coefficients experienced during flight. Also, at each time step, flight-recorded states, such as angle of attack, angle of sideslip, control surface positions, etc., are used to exercise the aerodynamic model in accordance with the aerodynamic model specification discussed previously. Each aerodynamic model element (i.e., pitching moment due to elevator, etc.) is stored and summed as prescribed in the aerodynamic model. By over-plotting the model predicted coefficients with the flight-extracted total coefficients, differences can be easily identified. Correlating the discrepancies with the excitation of the individual elements and parameters from the flight time history aids to isolate potential weaknesses in the aerodynamic model. A sample Overdrive result from a no-flap wing stall with the "All-Iced" configuration is shown in Figure 9.

\subsection{Description of the Ice Contamination Effects Flight Training Device - ICEFTD}

A platform to integrate the icing effects simulation models with hardware for pilot-in-theloop training sessions is currently being developed. The simulation models discussed in Section 2 are hosted by the Bihrle Applied Research D-Six ${ }^{\circledR}$ simulation software on a PC-based computer. D-Six uses state and pilot control inputs to calculate force and moments in real time to provide outputs from the equations of motion and update the graphics to the pilot. This platform is designed to be portable and utilize a desktop arrangement of components. These components are four flat panel monitors that sit on top of a desktop, a palletized pilot control and force feedback device that slides underneath the desktop, and two PC computers to run the software for the training sessions (Figure 10). A prototype version of the ICEFTD was developed for an early demonstration and is pictured in Figure 11.

A training-tool development software called Director will serve as an interface with D-Six and the hardware components. Director will host the training sessions by preparing the training pilot for the exercises and introducing additional icing training information to supplement the "hands-on" training with the FTD. An instructor station with Director designed option toggles will be used by an instructor to implement the training exercises and supplemental training information.

The pilot inputs used in ICEFTD are yoke and column deflections, rudder pedal deflection, flap deflection, and throttle position. The column has longitudinal force feedback modeled in D-Six based on elevator hinge moments to provide a critical cue on icing effects. Force feedback for the yoke (lateral) and rudder pedals is provided by spring resistance.

Four flat panel monitors provide an out-thewindow visual scene and a replication of an instrument panel. External views include a simple terrain and airport scenery with options for snow covered ground, night visuals, in-cloud obscuration (instrument meteorological conditions), and clear air conditions (visual meteorological conditions). Simulation fidelity for this device will be optimized by isolating the training pilot from the ambient environment through the use of curtains, and headsets. 
External views of the airplane are possible and may be utilized in a review of the training exercises. The instrument panel will display flight and navigation instruments so that the training pilot will be able to fly instrument approaches as well as other training exercises requiring precision control.

\subsection{Description of Training Exercises}

Three training blocks are briefly described below to teach pilots how to recognize and recover from iced-induced handling events. Each block contains exercises to instill specific knowledge to the training pilot. These blocks and exercises are potential functions available for an instructor to use in the ICEFTD.

It should be noted that the Airplane Flight Manual (AFM) for the DHC-6 prohibits the use of more than $10 \mathrm{deg}$. of flaps when any ice formation is known or suspected on the horizontal tailplane. However, for the purpose of training and technology demonstration, this limitation is ignored. It should also be noted, that the training exercises and scenarios presented herein were generated for the express purpose of evaluating the ICEFTD. Implementation of this technology in a full flight simulator would likely be done in accordance with a training syllabus tailored to regulatory requirements, aircraft type, and operator needs.

\subsection{Introduction and Basic Flying Qualities}

Training pilots will receive an overview briefing from the instructor, which will include effects of icing on the Twin Otter's handling characteristics $^{15}$. Initially, pilots will fly the simulator in its No-lce mode, to become familiar with basic handling characteristics and instrument approach procedures. This training will be flown in visual meteorological conditions (VMC) during the handling exercises, and in both VMC and instrument meteorological conditions (IMC) for the approaches. Specific exercises will include:

1. Takeoffs and departures

2. Cruise flight, turns to headings, climbs and descents, slow flight, stalls, and steep turns.

3. Precision, non-precision approaches and missed approach.

The use of the VMC mode will augment simulator fidelity, and help reinforce in the pilot's mind, normal aircraft response and handling characteristics. IMC to VMC transitions during approaches will provide further realism to the training exercises.

\subsection{Icing Effects on Aircraft Handling}

One of the benefits of this icing effects flight training device is the ability to make immediate changes in the flying characteristics due to icing at any point in a training session. This provides the opportunity for a pilot to execute a maneuver in a No-lce configuration, and then repeat that same maneuver in an "iced" configuration.

During this block of training, the instructor will begin the "icing" simulation in stages (Noice, tail only, then "all iced"), allowing the training pilot to see the progressive deterioration in aircraft handling as a function of flap position, speed, and power setting. The training pilot will perform the following series of tasks, and comment on flight characteristics during the execution of each task:

1. Pitch doublets: performed in each flap configuration at $\mathrm{V}_{\mathrm{FE}}$ or as designated by the instructor. These maneuvers will acquaint pilots with the changes in control response and damping characteristics in each critical icing configuration.

2. Flap transitions: wing flap position in the Twin Otter has a significant effect on aircraft handling with ice on the horizontal tail surfaces. This simulation will demonstrate how icing affects trimmability and handling at each flap position, and will provide significant tactile and visual recognition cues.

3. Speed transitions: these maneuvers will be flown with approach and landing flap settings, beginning at 1.1 $\mathrm{V}_{\mathrm{S}}$ with a slow acceleration to $\mathrm{V}_{\mathrm{FE}}$. As speed is increased, pilots will experience tactile feedback in the control column, and will associate this with an icing configuration.

4. Turns to headings during flap extension/retractions: these maneuvers will demonstrate how icing can affect precision aircraft control while maneuvering.

5. Power effects: by gradually increasing thrust from a power for level flight condition to maximum thrust available in the takeoff, approach, and landing flap configurations, pilots will 
experience how power is coupled to pitch control. Tail stalls will be experienced in the landing configuration, and the importance of power reduction during recovery will be emphasized.

6. Slow Deceleration to Stall: $1 \mathrm{knot} / \mathrm{sec}$ deceleration to a wing stall and recovery procedure, noting baseline vs. iced characteristics: Icing will affect stall handling, resulting in a sharp stall break and uncontrolled roll-off tendency. Pilots will recognize these characteristics and practice stall recoveries so as not to induce a secondary stall during the pull-out.

7. Full flap tail stall and recovery procedure in iced configuration only: Tail stalls, other than those due to power effects, will be initiated by aggressive pushover maneuvering. Pilots will recognize column force lightening, column pulsing, and learn to manage pitch inputs to avoid, or recover from tail stalls.

Recoveries from stall and handling events encountered during this training block will be instructed per the emergency procedures in Reference 5.

\subsection{Scenario-based Training}

This final block of training will require the pilot to apply knowledge gained in the previous blocks to scenarios similar to Line Oriented Flight Training (LOFT). This scenario will simulate a flight where icing conditions are encountered and the pilot is confronted with ice protection system failures that result in aircraft handling problems. For training purposes, it will be assumed that diversion is not possible and an instrument approach and landing is required at the destination airport. The training pilot will be vectored by the instructor, acting as Air Traffic Control, for an ILS approach and landing. The pilot will plan on completing the approach using normal procedures and configurations practiced in the initial block of training. As previously stated, the flap limitations in the DHC-6 AFM will be ignored for the purposes of this evaluation. When the pilot approaches minimums, and as the final selection of flaps is made for landing, visual contact will not be made with the landing environment, requiring a missed approach. The pilot will execute the missed approach and go around. During the subsequent approach, the pilot will be asked by the instructor to manage configuration so as to obtain the maximum amount of flap possible with acceptable handling characteristics, considering the possibility of another missed approach.

As an option, NASA may elect to expose some of the training pilots to the scenario based training immediately after the initial basic handling block is completed. The purpose of this will be to help NASA assess the value of the icing characteristics training relative to the instinctive reactions an uninitiated pilot may have to an unexpected handling event. The selection of the pilots for this option, if exercised, should involve varying experience levels.

\subsection{ICEFTD Evaluation}

The training exercises and multi-media support material will be organized into a syllabus format and implemented into the ICEFTD.

A workshop will be held to demonstrate the ICEFTD to a group of pilots that will serve as training pilots. These pilots will be briefed on the ICEFTD and syllabus by a training instructor. After the training sessions are completed, each pilot will be debriefed to record comments on the following:

1. Learning Achieved.

2. Usefulness of training.

3. Fidelity of simulation.

4. Recommendations for Improvement.

The results will be collated into a format that will provide an evaluation of the training, and whether or not the intended goals of the program were met.

\subsection{Summary}

As part of the Aviation Safety Program, NASA is developing an Ice Contamination Effects Flight Training Device (ICEFTD). The purpose of the ICEFTD is to demonstrate the technology and utility of a highly representative simulation for training pilots to recognize and recover from aircraft handling anomalies that result from airframe ice formations.

The icing effects simulation model development process required comprehensive 
wind tunnel tests on a sub-scale complete aircraft model with and without ice formations. Full-scale flight tests were performed to validate the simulation models.

The simulation models are being implemented into a PC-based platform for pilotin-the-loop simulations. Training exercises and multi-media training materials are being integrated into a curriculum to provide an instructor-led training session.

A group of pilots with varying levels of experience will be led through the training sessions to help evaluate the utility of the ICEFTD.

This effort will baseline a methodology for implementing an icing effects model in flight simulators, while demonstrating the potential safety gains from this type of training. Implementation of this technology in full flight simulators would likely be done in accordance with a training syllabus that is predicated on regulatory requirements, aircraft type, and operator needs. In the meantime, ICEFTD may be used as a stand alone training device, serving as an educational tool for pilots in general.

\section{References}

1. Russell, P., Pardee, J., Joint Safety Analysis Team Loss of Control, Final Report, December 2000

2. Tailplane Icing, NASA Glenn, video tape, $1998 . \quad$ http://icebox.grc.nasa.gov/ext/ education/video/video.html

3. Icing for Regional and Corporate Pilots, NASA Glenn, video tape, 1999 http://icebox. grc.nasa.gov/ext/education/video/video.html

4. Icing for General Aviation Pilots, NASA Glenn, DVD, 2002.http://icebox.grc.nasa.gov lext/ education/video/video.html

5. A Pilot's Guide to In-Flight Icing, NASA Glenn, CD-ROM, 2002 http://icebox.grc. nasa.gov/ext/education/cbt/cbt.html

6. Ranaudo, R.J., Batterson, J.G., Reehorst, A.L., Bond, T.H., Determination of Longitudinal Aerodynamic Derivatives Using Flight Data From an lcing Research Airplane, NASA TM 101427, January, 1989

7. Ranaudo, et al, The Measurement of Aircraft Performance and Stability and Control After Flight Through Measured Natural Icing Conditions, NASA TM-87265, April 1986

8. Ratvasky, T.P., Van Zante, J.F., Sim, A., NASA/FAA Tailplane Icing Program: Flight Test Report, NASA/TP 2000-209908, DOT/FAA/AR-99/85, March 2000
9. Van Zante, J.F., Ratvasky, T.P., Investigation of Dynamic Flight Maneuvers With an Iced Tailplane, NASA TM-208849, AIAA-99-0371, Jan. 1999

10. Ratvasky, T.P., Van Zante, J.F., In-Flight Measurements of an lced Horizontal Tailplane, NASA TM-208902, AIAA-990638, Jan. 1999

11. Papadakis, M., Gile-Laflin, B., Youssef, , Ratvasky, T., Aerodynamic Scaling Experiments with Simulated Ice Accretions, AIAA 2001-0833, January 2001

12. Barnhart, B., Dickes, E., Gingras, D., Ratvasky, T., Simulation Model Development for Icing Effects Flight Training, SAE 2002-01-1527, April 2002

13. Gingras, D., Dickes, E., Ratvasky, T., Barnhart, B., Modeling of In-Flight Icing Effects For Flight Training, AIAA-2002-4605, August 2002.

14. Ratvasky, T., Blankenship, K., Rieke, W., Brinker, D., Iced Aircraft Flight Data for Flight Simulator Validation, SAE-2002-011528, April 2002, NASA TM 2003-212114.

15. Ranaudo, R.J., Ratvasky, T.P., Van Zante, J.F., Flying Qualities Evaluation of a Commuter Aircraft with an Ice Contaminated Tailplane, NASA TM-2000-210356 SAE 2000-01-1676, May 2000. 


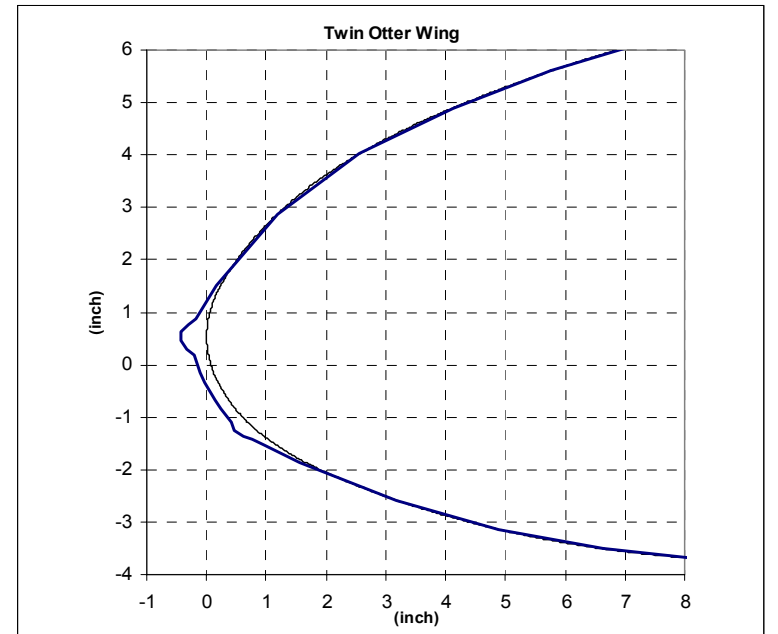

Figure 1. Simulated Wing Ice Profile

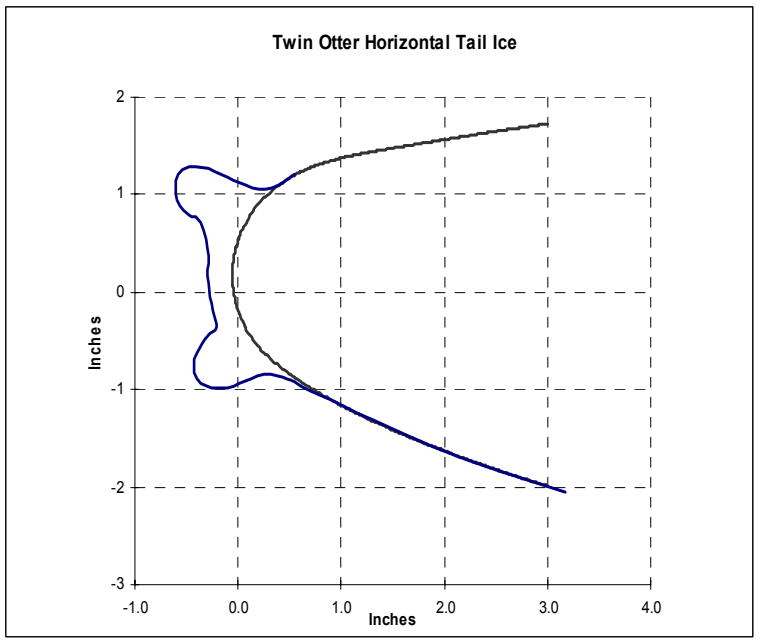

Figure 2. Simulated Horizontal Tail Ice Profile

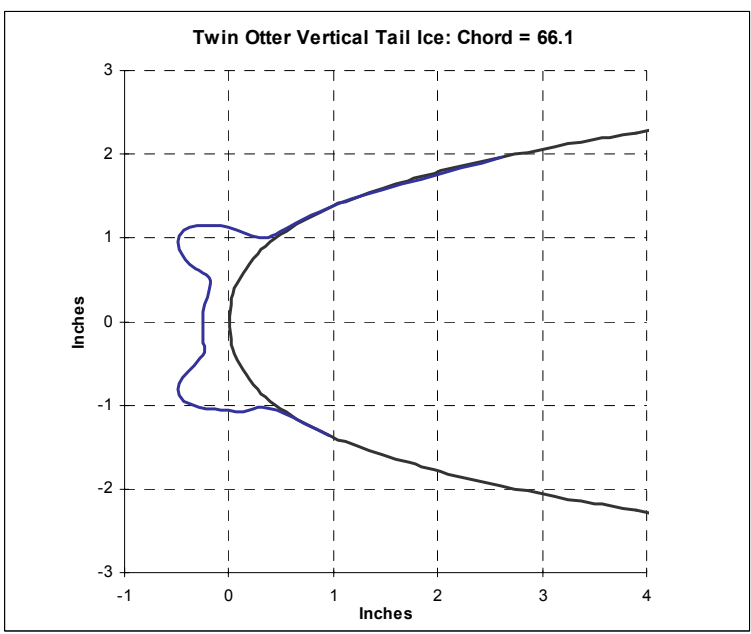

Figure 3. Simulated Vertical Tail Tip Ice Profile

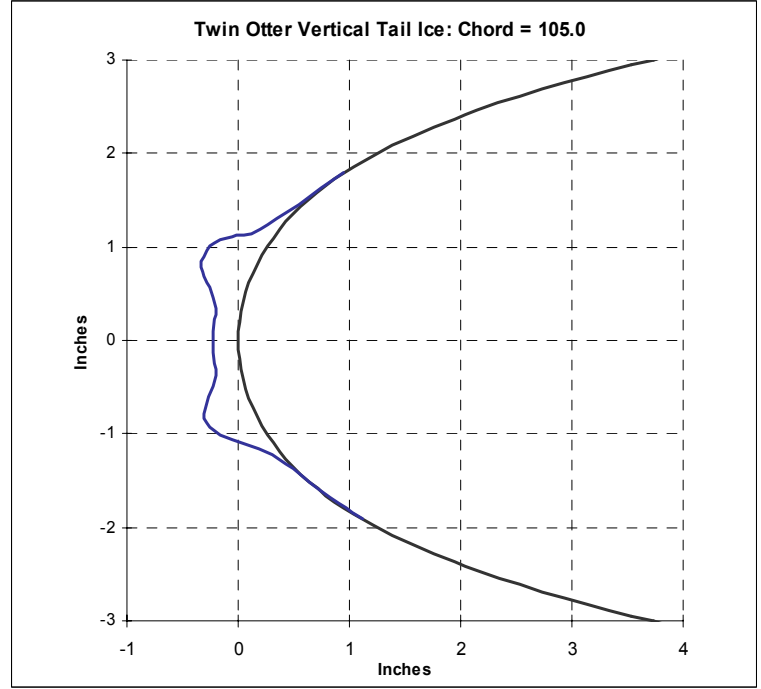

Figure 4. Simulated Vertical Tail Root Ice Profile

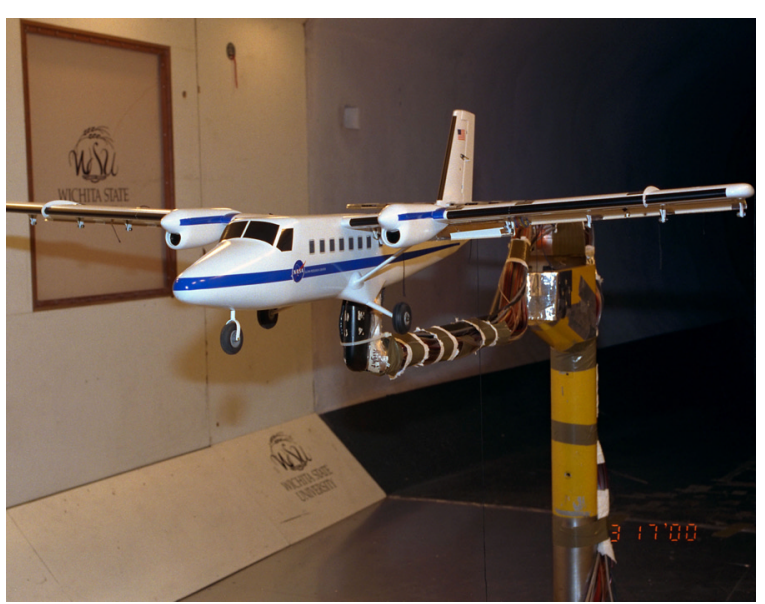

Figure 5. 6.5\%-Scale Twin Otter model in WSU 7'x10' Low-Speed Wind Tunnel

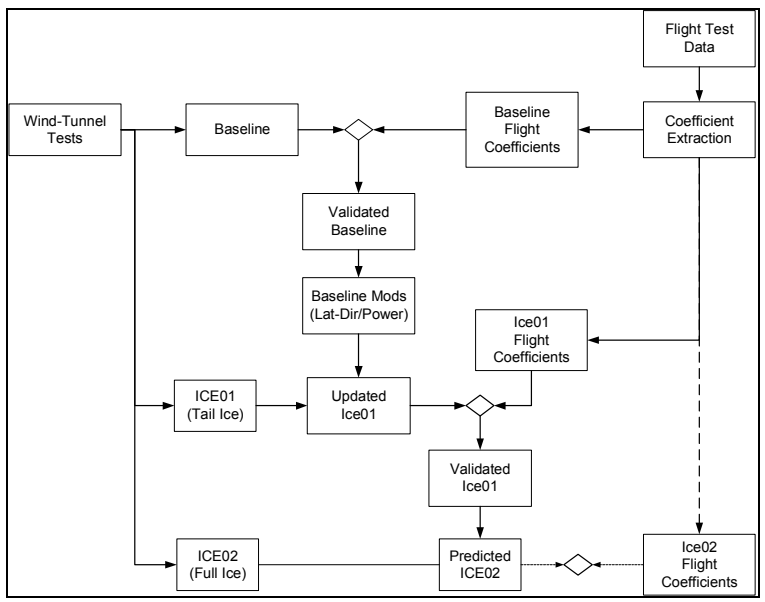

Figure 6. Simulation Model Development Process 


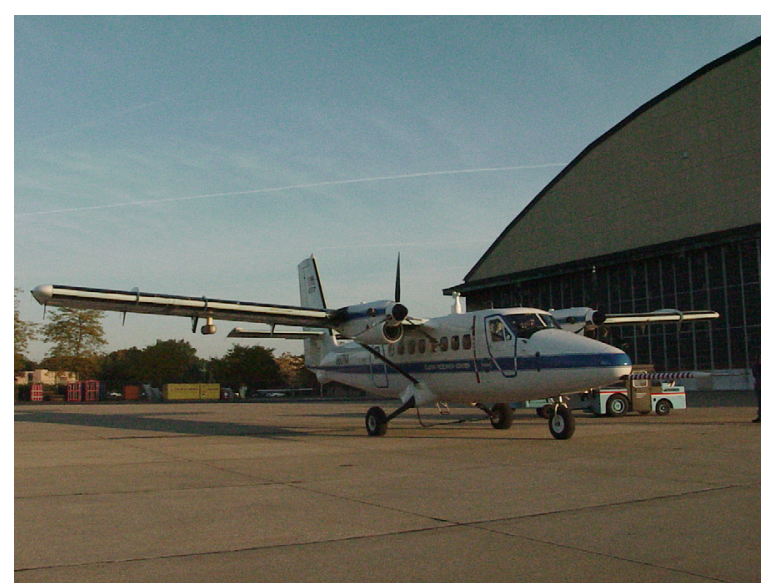

Figure 7. NASA Twin Otter in "All-Iced" Configuration

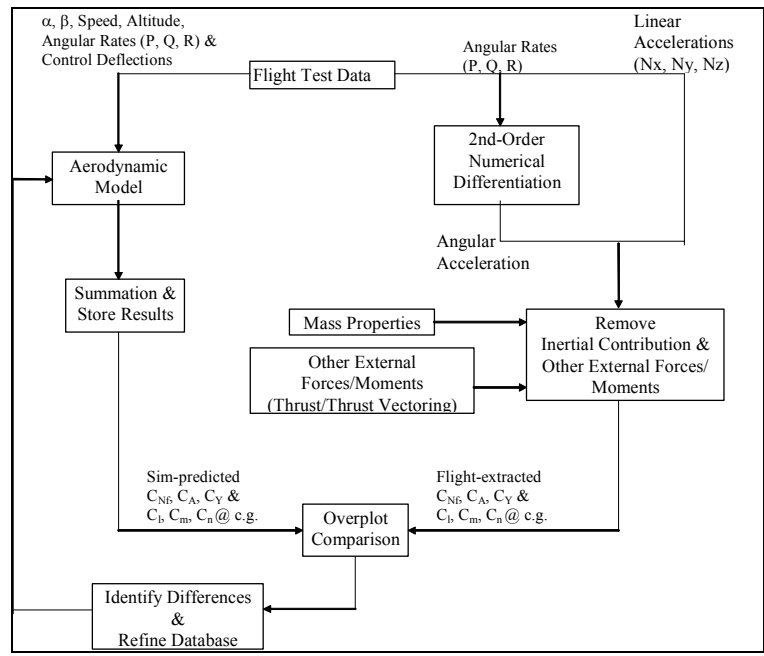

Figure 8. Simulation Model Validation Process
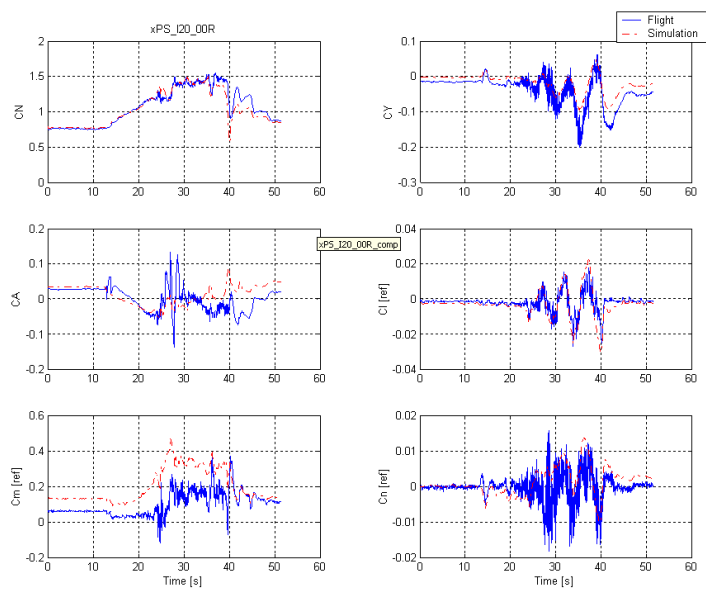

Figure 9. Sample Overdrive result from a no-flap wing stall with the All Iced configuration

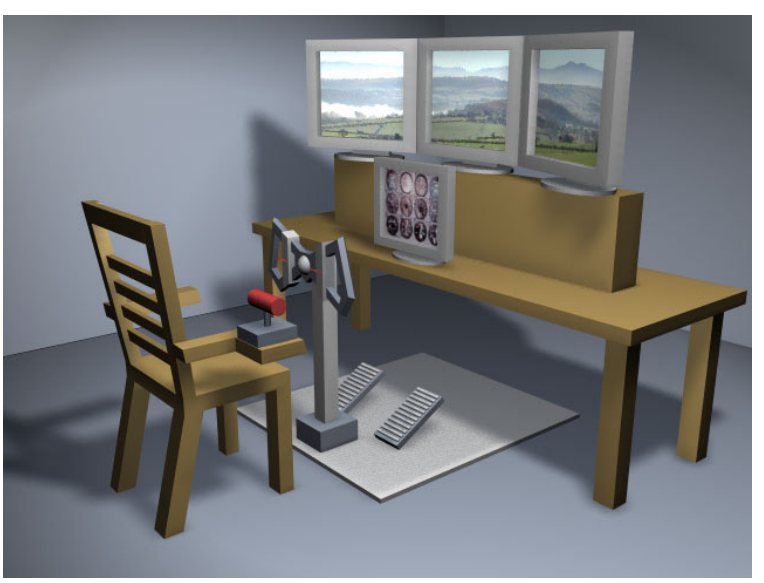

Figure 10. ICEFTD Rendering

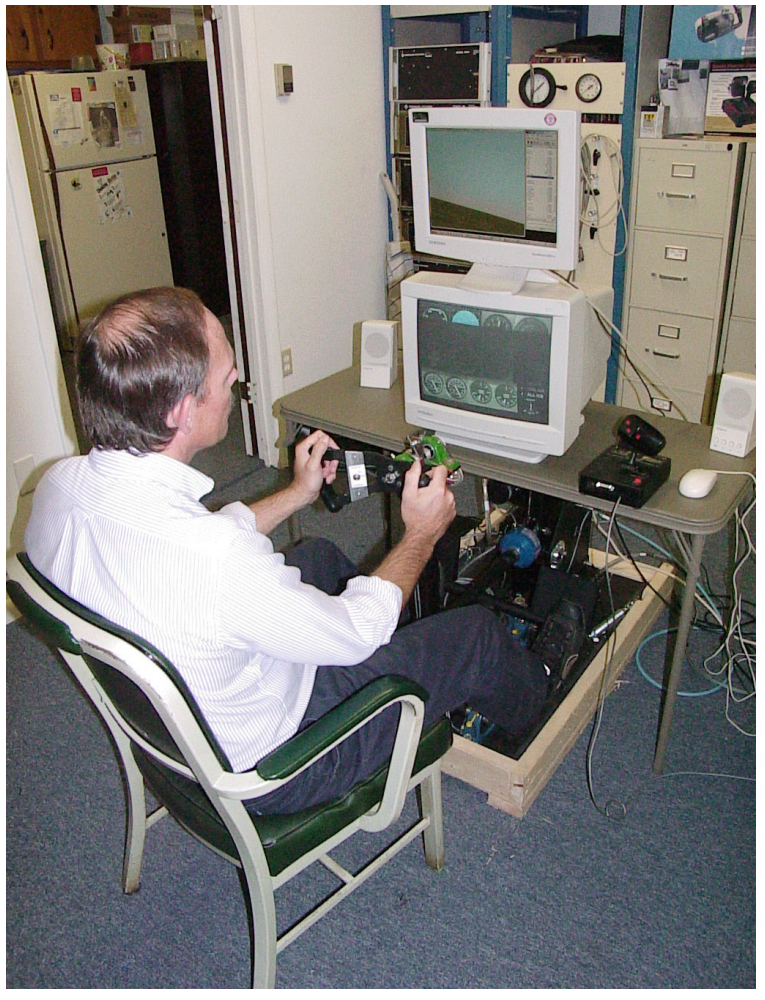

Figure 11. Proto-type ICEFTD 


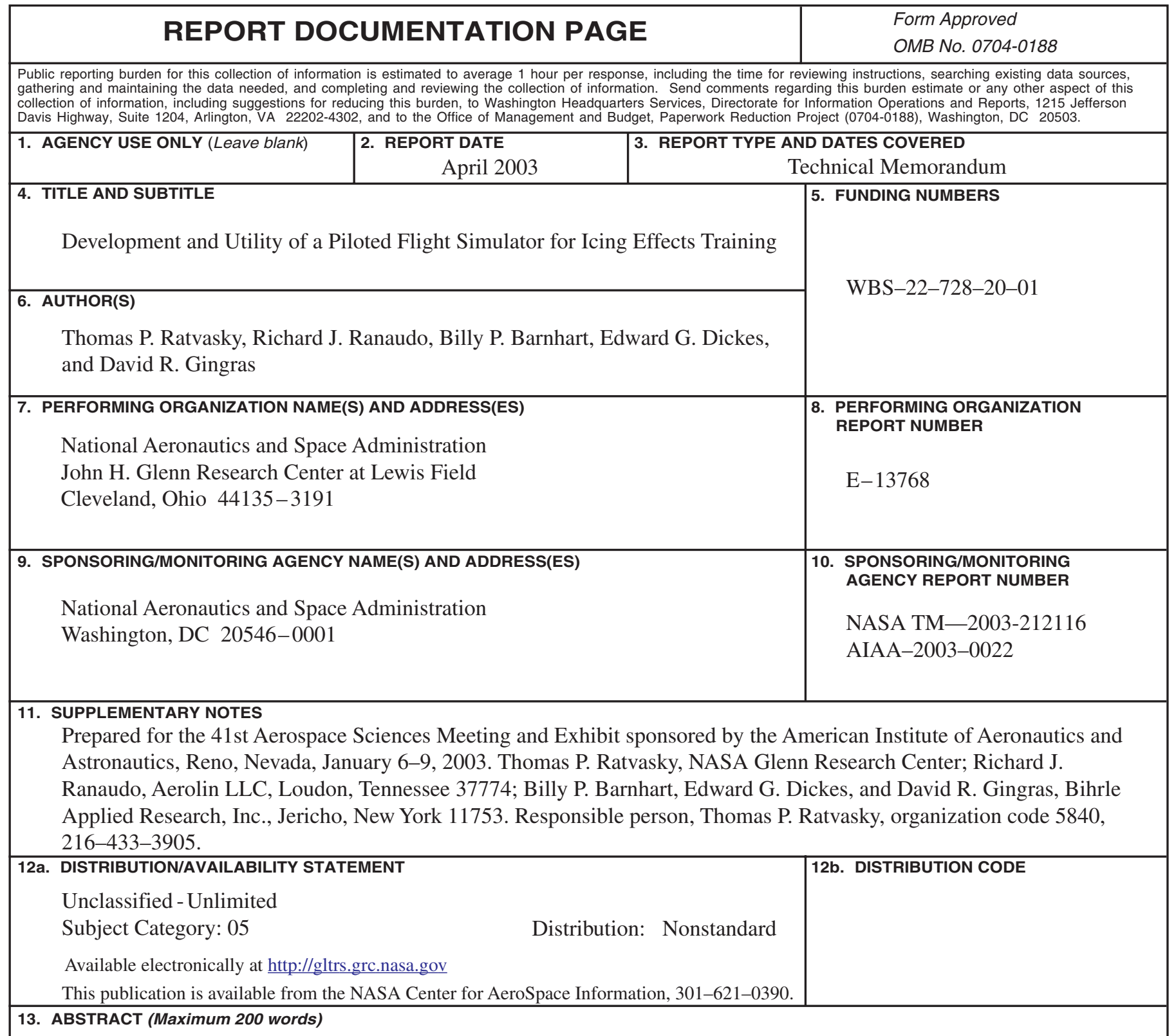

A piloted flight simulator called the Ice Contamination Effects Flight Training Device (ICEFTD), which uses low cost desktop components and a generic cockpit replication is being developed. The purpose of this device is to demonstrate the effectiveness of its use for training pilots to recognize and recover from aircraft handling anomalies that result from airframe ice formations. High-fidelity flight simulation models for various baseline (non-iced) and iced configurations were developed from wind tunnel tests of a subscale DeHavilland DHC-6 Twin Otter aircraft model. These simulation models were validated with flight test data from the NASA Twin Otter Icing Research Aircraft, which included the effects of ice on wing and tail stall characteristics. These simulation models are being implemented into an ICEFTD that will provide representative aircraft characteristics due to airframe icing. Scenario-based exercises are being constructed to give an operational-flavor to the simulation. Training pilots will learn to recognize iced aircraft characteristics from the baseline, and will practice and apply appropriate recovery procedures to a handling event.

14. SUBJECT TERMS

Aircraft icing; Flight simulation; Flight simulators; Flight safety

\begin{tabular}{|c|c|c|c|}
\hline $\begin{array}{c}\text { 17. SECURITY CLASSIFICATION } \\
\text { OF REPORT } \\
\text { Unclassified }\end{array}$ & $\begin{array}{c}\text { 18. SECURITY CLASSIFICATION } \\
\text { OF THIS PAGE } \\
\text { Unclassified }\end{array}$ & $\begin{array}{c}\text { 19. SECURITY CLASSIFICATION } \\
\text { OF ABSTRACT } \\
\text { Unclassified }\end{array}$ \\
\hline
\end{tabular}

NSN 7540-01-280-5500

Standard Form 298 (Rev. 2-89)

Prescribed by ANSI Std. Z39-18 298-102 

